\title{
Macrobenthic prey and physical habitat characteristics in a western Gulf sturgeon population: differential estuarine habitat use patterns
}

\author{
Mark S. Peterson ${ }^{1, *}$, Jeanne-Marie Havrylkoff ${ }^{1}$, Paul O. Grammer ${ }^{1}$, Paul F. Mickle ${ }^{1}$, \\ William T. Slack ${ }^{2}$, Kevin M. Yeager ${ }^{3}$ \\ ${ }^{1}$ Department of Coastal Sciences, The University of Southern Mississippi, 703 East Beach Drive, Ocean Springs, \\ Mississippi 39564, USA \\ ${ }^{2}$ U.S. Army Corps of Engineers, Environmental Research and Development Center, 3909 Halls Ferry Road, Vicksburg, \\ Mississippi 39180, USA
}

${ }^{3}$ Sedimentary, Environmental, and Radiochemical Research Laboratory, Department of Earth and Environmental Sciences, University of Kentucky, Lexington, Kentucky 40506, USA

\begin{abstract}
Gulf sturgeon Acipenser oxyrinchus desotoi is listed as 'threatened' under the US Endangered Species Act throughout its range in the northern Gulf of Mexico, with Mobile Bay, Alabama, USA, as the recognized break between eastern and western populations. Population recovery requires protection of the species and its critical habitat. We examined Gulf sturgeon physical habitat attributes and infaunal macrobenthic prey density and composition both spatially and seasonally relative to acoustically tagged Gulf sturgeon occurrence in the Pascagoula River estuary. Gulf sturgeon occupancy patterns indicated that adults move quickly through the system during fall and spring compared to longer but more spatially and temporally variable occupancy for juveniles and sub-adults in both seasons; sub-adults exhibited a less spatially and temporally variable occupancy pattern. We found significant differences in physical habitat and macrobenthic density characteristics that partially explained Gulf sturgeon spatial and temporal occupancy patterns. Direct comparisons of physical drivers (\% silt, depth, particulate organic carbon) and macrobenthic density patterns (BEST procedures) were significantly correlated $(p<0.01)$ but weak (global $R=0.277$ ) and suggest alternate hypotheses to better explain the differential estuarine habitat use patterns. The most parsimonious explanation with multiple weights-of-evidence suggests reduced use of the eastern distributary habitat by Gulf sturgeon based on synergistic effects of urbanization and industrialization such as bulkheading, channelization, dredging and related maintenance activities, and beach re-nourishment, all of which occur almost exclusively in the east zone of the estuary.
\end{abstract}

KEY WORDS: Acipenser oxyrinchus desotoi - Alteration - Critical feeding habitat - Depth · Benthos $\cdot$ Habitat use $\cdot$ Sediments

\section{INTRODUCTION}

Eighty-five percent of all sturgeon species on Earth are at risk of extinction, placing them on the International Union for the Conservation of Nature Red List of Threatened Species (IUCN 2010). Historical overfishing and population declines due to human devel- opment (e.g. dams; Smith 1985, Cooke et al. 2012) are problematic to the recovery of sturgeons, many of which do not spawn annually and are long lived (Dadswell 2006, Nelson et al. 2013). In the USA, the Gulf sturgeon Acipenser oxyrinchus desotoi is a federally listed threatened species (Smith \& Tillman 1991), and many of the river, bay, and nearshore areas 
throughout its range are considered critical habitats that support spawning, in-river holding, or feeding activities (Knowles \& Manson 2003). Gulf sturgeon occur in drainages from the Suwannee River, Florida, to the Pearl River, Louisiana (Wooley 1985, Rogillio et al. 2007), where they spawn in upriver reaches during the early spring (Sulak \& Clugston 1998, Heise et al. 2004), and young-of-the-year spend 6 to $10 \mathrm{mo}$ feeding in-river as they migrate down river before they appear in the estuary in December to February (Sulak \& Clugston 1998, Havrylkoff et al. 2012). Juveniles (<6 yr, except young-of-the-year) are believed to overwinter in the estuary (Sulak \& Clugston 1998, 1999, Sulak et al. 2009). In Mississippi, large sub-adult and adult Gulf sturgeon overwinter in the Mississippi Sound, congregating near the passes between barrier islands (Rogillio et al. 2007, Ross et al. 2009). The estuary provides a vital ontogenetic link in the life history of Gulf sturgeon, ranging from a travel corridor connecting vital spawning and summer in-river holding areas, to nearshore and offshore marine feeding areas (Ross et al. 2009, Havrylkoff et al. 2012).

Known prey items of Gulf sturgeon are based on descriptions of stomach contents from individuals sampled before the species was listed (Boschung \& Malloy 1956, Huff 1975, Carr 1983, Tatum 1984, Mason \& Clugston 1993, Carr et al. 1996), from mortalities (Heard et al. 2002), or from individuals subjected to gastric lavage (Murie \& Parkyn 2001, 2002), with the vast majority of diets based on specimens from Florida. It is clear, however, that diets vary ontogenetically (Huff 1975, Mason \& Clugston 1993) across their range because of zoogeographic differences in prey distribution (Parauka et al. 2011), as well as water depth and sediment composition (Fox et al. 2002, Harris et al. 2005). Moreover, quantifying benthic resource distribution coupled with sediment characteristics are surrogate approaches used to identify primary sturgeon foraging areas (Fox et al. 2002, Brooks \& Sulak 2005, Harris et al. 2005, Nellis et al. 2007, Ross et al. 2009). These data suggest that Gulf sturgeon, like most sturgeon, are opportunistic benthic foragers (Huff 1975, Miller 2004, Vecsei \& Peterson 2004, Parauka et al. 2011) as Breder (1929) showed in his detailed description of sturgeon foraging behavior. Sturgeon use barbels, snout and head electroreceptors, their specialized tubular mouth, and suction feeding (Miller 2004, Vecsei \& Peterson 2004) to obtain prey from sediments. As past natural and anthropogenic events can be recorded as layers in the sediment, they are considered the 'memory' of ecosystem change; thus benthic assemblages appear to reflect temporal and spatial change in the environment due to accumulated environmental stress (Dean 2008, Montagna et al. 2013).

The objective of this study was to quantify spatial and seasonal occupancy and habitat use patterns by acoustically tagged juvenile, sub-adult, and adult Gulf sturgeon relative to benthic resource availability and physical habitat characteristics in the Pascagoula River estuary. Our approach allows assessment of habitat use by this threatened fish in a region where extensive development is occurring, including channel dredging and maintenance, marsh creation from dredge materials, and beach re-nourishment activities. Specifically, we (1) quantitatively assessed infaunal macrobenthic density and composition, grain size, particulate organic carbon (POC), and depth seasonally and spatially; (2) quantified Gulf sturgeon occupancy relative to seasonal and spatial patterns of prey availability and physical habitat differences using passive acoustic telemetry; and (3) determined the relationship between depth, grain size, POC, and macrobenthic density patterns that characterize the habitat template (sensu Southwood 1977) of the threatened western population of Gulf sturgeon in the Pascagoula River estuary.

\section{MATERIALS AND METHODS}

\section{Study site}

The Pascagoula River, located in southeastern Mississippi (Fig. 1), is the last large river system within the conterminous USA with no dams or impoundments on the main channel (Dynesius \& Nilsson 1994). This unimpeded river divides to form 2 distributaries considerably north of the mouth, but the first 12 river $\mathrm{km}(\mathrm{rkm})$ of the eastern distributary have a regularly dredged ship channel and a large shipyard (Figs. 1 \& 2). Farther east is Bayou Casotte, a developed harbor area with a regularly dredged ship channel (Fig. 2). Dredged materials from both channels and harbors are deposited mainly south of the study area along the west side of the Pascagoula River ship channels out toward the barrier islands in at least 9 disposal areas (J. Jacobsen pers. comm.). Between the east Pascagoula distributary and Bayou Casotte is the beach front of the city of Pascagoula which was recently re-nourished (Fig. 2) between 3 August 2009 and 13 April 2011 (J. MacDonald pers. comm.). The western distributary is a minimally impacted shallow salt marsh habitat (Peterson et al. 2007, Havrylkoff et al. 2012), and Bayou Chemise is a 


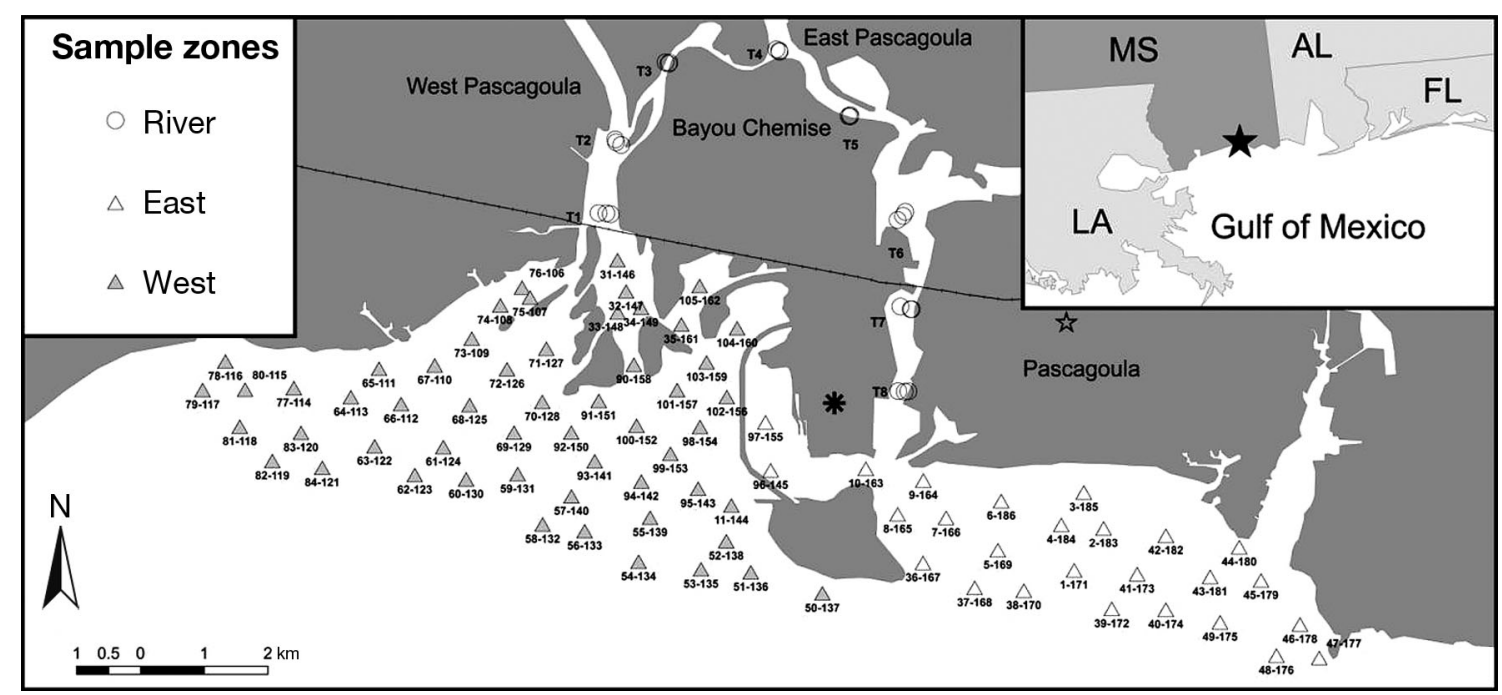

Fig. 1. Benthic station numbers by zone; inset shows study location within the state of Mississippi, USA. On the base map, open

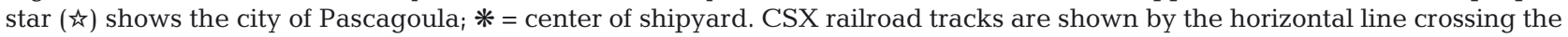
west and east Pascagoula River

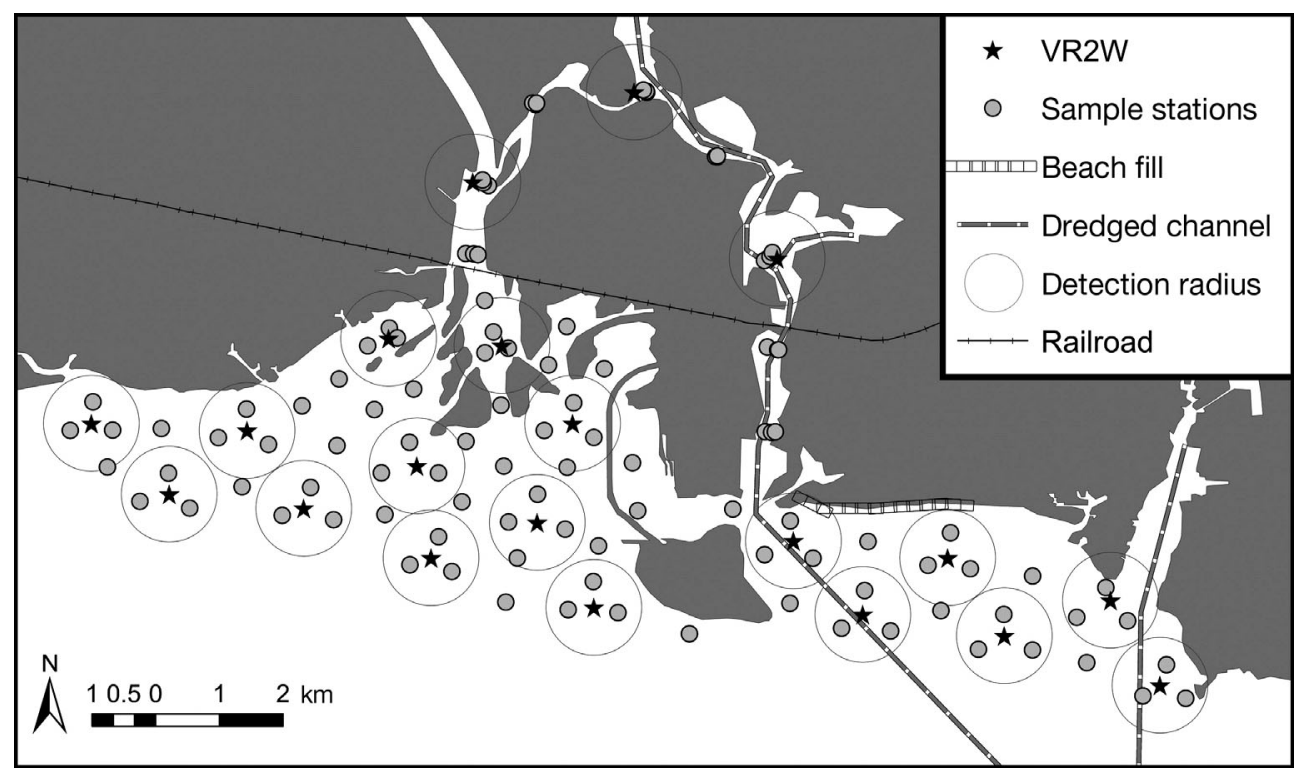

Fig. 2. Benthic sample stations (O) relative to VR2W receiver locations and detection areas (star and large circles) coupled with the locations of the CSX railroad tracks, the dredged channels, and the re-nourished beach front

natural tributary that provides a connection between the 2 distributaries close to its terminus (Fig. 1).

\section{Benthic sampling}

We collected 210 benthic and sediment samples divided by season (fall and spring) across the study region; Figs. $1 \& 2$ show the relation of the benthic and sediment stations (680 to $750 \mathrm{~m}$ distance between stations) within each of the receiver detection zones (east, west, river) and additional stations distributed among the receivers. Station locations in Figs. $1 \& 2$ are based on the geometric mean of the fall and spring station GPS coordinates. The 105 fall benthic and sediment samples were collected from 13 to 15 December 2010, and the 105 spring samples were collected from 30 March to 1 April 2011. Surface water temperature $\left({ }^{\circ} \mathrm{C}\right)$, salinity, dissolved oxygen (DO, $\mathrm{mg} \mathrm{l}^{-1}$ ), and specific conductivity $(\mathrm{mS})$ were recorded with a YSI handheld meter (Model 85), and water depth (m) was measured with 
a Hondex Digital handheld depth sounder for each station.

A single benthic sample was collected with a Petite Ponar grab sampler (area $=0.0231 \mathrm{~m}^{2}$ ) deployed from a boat at each station. In cases where the substrate consisted entirely of fine-grained material, samples were directly screened through a $0.5 \mathrm{~mm}$ sieve in the field. About $90 \%$ of the samples were processed with this method. For the remaining samples that contained coarse-grained material (e.g. shell hash), samples were initially washed through a $1.0 \mathrm{~mm}$ sieve to recover large or heavy organisms (e.g. gastropods, bivalves), and the filtrate was subsequently washed through a $0.5 \mathrm{~mm}$ sieve to retain lighter fractions in the field. All processed samples were labeled, fixed with $10 \%$ formalin, and returned to the laboratory.

\section{Laboratory analysis}

Samples were initially stained with Rose Bengal to facilitate picking and identification. Macrobenthic invertebrates were sorted into major taxonomic groups and transferred to $70 \%$ ethanol. Subsequently, specimens were identified to the lowest practical taxonomic level (usually species) using available literature (Johnson \& Uebelacker 1984, Abele \& Kim 1986, Kensley \& Schotte 1989, Heard et al. 2003, 2007, LeCroy 20042011, Tunnel et al. 2010), and enumerated on a per $\mathrm{m}^{2}$ basis. Some poorly known groups, like the nemerteans, were not identified beyond phylum or class level. All specimens extracted from the samples were retained for deposit in the invertebrate zoology collection at the University of Southern Mississippi, Gulf Coast Research Laboratory.

\section{Sediment processing}

Near surface ( 0 to $5 \mathrm{~cm}$ ) sediment samples were collected and bulked in the field using a Petite Ponar grab sampler, including sediments from at least 3 independent samplings within a $2 \mathrm{~m}^{2}$ radius at each station. The location of each station was recorded with differential GPS. Samples were stored in labeled plastic bags and transported to the laboratory where they were initially wet-sieved through a $2 \mathrm{~mm}$ sieve to identify larger size fractions (if any), and these were dried and weighed. Prior to detailed analyses of inorganic sediment grain size fractions (sand, silt, and clay; sensu Folk 1980) and distributions, sedimentary organic matter was destroyed by oxidation using $\mathrm{H}_{2} \mathrm{O}_{2}$ (Day 1965). Subsequently, sediment samples were an- alyzed using a Malvern Mastersizer 2000 and hydrodispersion unit, allowing sediments to be analyzed while in suspension. This laser-optical particle size characterization instrument has a dynamic range of 0.02 to $2000 \mu \mathrm{m}$ with outstanding accuracy $(+1 \%)$ and precision (better than $1 \%$ relative standard deviation). Sedimentary POC $\left(\mu \mathrm{g} \mathrm{m}^{-1}\right)$ was determined by first treating samples with $\mathrm{HCl}$ acid fumes to destroy any carbonates present (Hedges \& Stern 1984, Harris et al. 2001) followed by elemental analyses using a 4010 CHN/SO Analyzer (Costech Analytical Technologies).

\section{Gulf sturgeon tagging procedures}

Gulf sturgeon were captured with anchored multifilament $(60.9 \times 3.0 \mathrm{~m}, 20.3 \mathrm{~cm}$ bar mesh or $45.7 \times$ $3.0 \mathrm{~m}, 12.7 \mathrm{~cm}$ bar mesh) and monofilament $(71.0 \mathrm{~m} \times$ $2.4 \mathrm{~m}, 5.1 \mathrm{~cm}$ bar mesh) gill nets set on the bottom parallel and perpendicular to flow just upriver of where the distributaries diverge (Havrylkoff et al. 2012, census location, rkm 26; see their Fig. 1). Nets were checked every $2 h_{\text {; }}$ captured Gulf sturgeon were weighed (nearest $0.1 \mathrm{~kg}$ ) and measured for fork length (FL, $\mathrm{cm}$ ) and assessed for external tags and internal passive integrated transponder (PIT) tags. New captures were tagged with T-bar and PIT tags as described by Heise et al. (2004). Juvenile and subadult fish were tagged externally at the base of the dorsal fin (Sulak et al. 2009, Havrylkoff et al. 2012) with uniquely coded low-powered acoustic tags (either Model V9-2L or V13-1L; 69 kHz; 90 s mean random delay; VEMCO). Adult fish were tagged internally (USFWS 1993, Moser et al. 2000) with high-powered uniquely coded and coated (clear Platinum Silicone Elastomer) V16-6H acoustic tags (69 kHz; $90 \mathrm{~s}$ mean random delay). Beta-dyne ${ }^{\circledR}$ impregnated petroleum jelly was used on all tagging wounds. Captured Gulf sturgeon were categorized as adult (>125.0 cm FL), sub-adult (89.1-125.0 cm FL), and juvenile (30.4-89.0 cm FL; Parauka et al. 2011).

\section{Automated telemetry arrays}

Anchored (68 kg concrete blocks) automated VEMCO VR2W receivers (hereafter collectively an 'array') tracked movement of all tagged Gulf sturgeon within the river and estuarine zones (west and east; Fig. 2). Receivers were attached to an aluminum buoy pipe and were allowed to pivot with any buoy movements. Receiver bottoms were positioned about $1 \mathrm{~m}$ below the surface in a top-down orientation with 
an assumed maximum detection radius of $750 \mathrm{~m}$ (Sulak et al. 2009, Havrylkoff et al. 2012) to maximize coverage and minimize duplicate detections. The overall array was deployed on 5 October 2010 as part of a $3 \mathrm{yr}$ study, but for the present study, acoustically tagged Gulf sturgeon detections were only analyzed for $45 \mathrm{~d}$ before or after the middle day of each seasonal benthic sampling date (see below). Station ambient environmental characteristics were only measured when benthic and sediment samples were collected. The fall period was between 20 October 2010 and 28 January 2011, and the spring period was between 14 February 2011 and 1 April 2011. Detections from each study period were sorted by tag number and then placed in chronological order, and the time between successive detections for each fish (tag number) was calculated. Duplicate detections were considered instances when detections were recorded on more than 1 receiver with the time between detections being shorter than the minimum tag interval minus $10 \mathrm{~s}$ (to account for receiver clock drift). The presence of a duplicate may cause a false triplicate detection to appear in the database. In such cases, the first detection was kept, the first duplicate was then removed, and the time from the original detection to the next successive one was recalculated to see whether it passed or failed the detection test. We developed a weighted detection index in order to estimate occupancy of array zones while accounting for differences in the number of receivers (west $=11$, east $=6$, river $=3$ ) and thus detections within and among Gulf sturgeon size classes $(n=3)$. The index was applied to the detection database after duplicate detections were removed. First, we accounted for the different number of receivers in each zone by calculating an effort-adjusted value $(w=1-$ [no. of receivers in zone / total no. of receivers] as a proportion) and multiplied that weighting factor $(w)$ by the number of detections for each fish within each respective zone. We then normalized (Z-scores) these weighted detections $\left(W \times X_{i}\right)$ for each individual by zone and season using Eq. (1) below; the global mean $\left(\bar{x}_{\mathrm{g}}\right)$ and global standard deviation $\left(\mathrm{SD}_{\mathrm{g}}\right)$ of detection numbers were based on the sum of all detections across the entire array for all Gulf sturgeon detected:

$$
\left[\left(W \times x_{i}\right)-\bar{x}_{g}\right] / \mathrm{SD}_{\mathrm{g}}
$$

Our calculated index can be used for any system under study because the $Z$-scores are based on the global mean and standard deviation estimates and the number of tagged fish. Index values can be scaled for a system by adding the lowest index value (corresponding to effort-adjusted 0 detection) to all values, thus making the lowest scaled index value 0 . Moreover, the final effort-adjusted, normalized, and scaled detection index (hereafter occupancy index) values can then be interpreted as the mean number of detections by size class within a zone and season relative to a global number of detections observed within the entire array with both seasons pooled. High values indicate that a greater number of detections were recorded, on average, for a size class within a particular zone relative to the overall mean number of Gulf sturgeon detections.

\section{Data analysis}

\section{Univariate analyses}

Underwood (1997) clearly outlined why ANOVAs are robust to violations of non-normal distributions and heterogeneous variances and suggested, assuming transformations do not correct these issues, using these tests as exploratory analyses. We followed his suggestions for all univariate tests in this study. Thus, in order to simply describe the environmental conditions during macrobenthic sampling, we first compared Shannon diversity $\left(H^{\prime}\right)$ and Simpson's evenness $(1-\lambda)$ (Clarke \& Gorley 2006), water quality, depth, and sediment variables each separately across zones $(n=3)$ and seasons $(n=2)$ for the full data set with a 2-way ANOVA. We then followed each analysis for zone with a 1-way ANOVA pooled by season and Student's $t$-tests within zone by season as it was predicted a priori that season would create sufficient variability within zone to cause a significant interaction term. The homogeneity of variance and normality assumptions were tested, and if violated, data were $\left(\log _{10}\right)$ transformed prior to analysis. If $F$-values indicated significant differences between groups, either a Sidak (homogeneous variance) or GamesHowell ( $\mathrm{GH}_{\text {; }}$ heterogeneous variance) post hoc test was used to separate mean responses (Field 2005). If a significant interaction term was computed, the partial eta squared (partial $\eta^{2}$, effect size) values were used to interpret their importance relative to the main effects. Partial $\eta^{2}$ is the proportion of the total variation attributable to a factor excluding the other main factors and other interactions (Green \& Salkind 2008). The values range from 0 to 1 , with higher numbers indicating a larger effect size.

For Gulf sturgeon occupancy comparisons, we conducted a similar 2-way ANOVA on normalized values and used the outcome to initially assess seasonal differences. No significant difference was found by 
season ( $p>0.05$ ); therefore, we pooled the data by season for a 1-way ANOVA and GH post hoc tests across zones. All statistics were conducted with SPSS software (version 20.0), and significance was designated when $\mathrm{p} \leq 0.05$ (Field 2005).

\section{Multivariate analyses}

The following analyses only included data from the east and west zones seasonally as the river zone was sampled at shallow, middle, and channel stations within each transect (Tables S1 \& S2 in the Supplement at www.int-res.com/articles/suppl/n022p159_ supp.pdf); thus, the data are not directly comparable to the data collected in the other 2 zones. These data are provided to enable examination of a complete set of environmental parameters for the macrobenthos and the conditions in which acoustically tagged Gulf sturgeon were detected.

Two multivariate approaches were used: (1) ordinate the 5 physical variables (\% sand, \% silt, \% clay, POC, water depth) by zone (east and west zones only) and season across the estuarine portion of the Pascagoula River estuary, and (2) compare the physical data and macrobenthic density data by zone and season. First, we used a principal components analysis (PCA) on the 5 normalized ( $[\mathrm{x}-\overline{\mathrm{x}}] / \mathrm{SD}$ ) physical variables in order to reduce them into intercorrelated sets of variables (components) based on a correlation matrix (Field 2005, Clarke \& Gorley 2006). We considered any variable that loaded on a component at $|\geq 0.400|$ to make a significant contribution to interpreting that component (Hair et al. 1984).

The second approach determined which physical variables were correlated to the macrobenthic pattern in ordination space. Ponar grab sample volumes can vary with sediment type (Ross et al. 2009); thus we initially standardized data by sample totals within strata ( $\mathrm{n}=4$; zone/season combinations). All analyses were limited to taxa comprising $\geq 1 \%$ of density estimates ( $\mathrm{n}=33$ taxa) for all samples regardless of zone or season. The totals were then square-root transformed to reduce the influence of abundant taxa. A non-metric multi-dimensional scaling (MDS) procedure was used to ordinate ranked macrobenthic density values with the Bray-Curtis similarity coefficient. This analysis attempts to create assemblages by season (fall and spring) and zone (east and west) based on transformed macrobenthic density samples through a generated similarity matrix and then plot them in ordination space. Values that are spatially closer in the MDS plot mean that the assemblages are more similar, and those farther apart indicate that they are not as similar.

Levels of similarity among macrobenthic stations based on square-root transformed density were compared by zone and season with a full-factorial permutational multivariate ANOVA (PERMANOVA; permutations = 9999; Anderson et al. 2008). The square root of the estimated variance components was used to assess the importance of significant main effects and interaction terms (Anderson et al. 2008). Pairwise a posteriori comparisons were made using the multivariate analogue of the $t$-test (pseudo- $t$ ) for each level of significantly different main effects and interaction terms. If there was a significant interaction term, then pseudo-t-tests were used to compare levels within each term of the interaction (Anderson et al. 2008). The homogeneity of multivariate dispersion (PERMDISP; hereafter HMD) was used to delineate the deviation from centroids in macrobenthic density among zones and seasons separately based on the squareroot transformed Bray-Curtis similarity matrix (Anderson et al. 2008). As a guide to understanding taxaspecific differences, a similarity percentages (SIMPER) analysis based on ranked similarity was used to disaggregate the similarity matrix and identify which taxa were most responsible for any dissimilarity among zones and seasons (Clarke \& Gorley 2006).

Finally, we used the non-parametric BEST procedure that conducts Spearman's rho rank correlations ( $\rho$ ) to determine the extent of pattern-matching between the square-root transformed and normalized physical variables resemblance matrix and the squareroot transformed resemblance matrix for the macrobenthic assemblages. This approach searches all possible combinations of physical variables (BIOENV function) in order to identify the subset of physical variables that give the best correlative explanation of the macrobenthic assemblage structure. All multivariate analyses were performed with PRIMER version 6.1.6 (Clarke \& Gorley 2006). Subsequent to these analyses, we used Spearman's rho $(\rho)$ correlations between the subset of driving physical variables from BEST and the reduced set of macrobenthic taxa density to estimate the strength and direction of the paired relationship.

\section{RESULTS}

\section{Univariate analyses}

As predicted a priori, all ANOVAs had heterogeneous variances, but only water temperature was 
Table 1. Summary of all 2-way ANOVAs (zone and season), 1-way ANOVA (zone only), and Student's t-test (season only). The values for all ANOVA tests were $\log _{10}$ transformed prior to analysis to stabilize variances except Shannon diversity $(H)$ and Simpson's evenness $(1-\lambda)$, which were analyzed using non-transformed data. Most data were normal (except water temperature), but all had heterogeneous variances (except \% clay) even after transformation. Z: zones (E: east, W: west, R: river), S: season (fall and spring), I: interaction, post hoc: Games-Howell (non-homogeneous) test, na: no difference

\begin{tabular}{|c|c|c|c|c|c|c|c|}
\hline \multirow[t]{2}{*}{ Comparisons } & \multicolumn{3}{|c|}{ 2-way ANOVA -} & \multicolumn{3}{|c|}{ - 1-way ANOVA } & \multirow{2}{*}{$\begin{array}{c}t \text {-test } \\
\text { Fall-spring }\end{array}$} \\
\hline & F & $\mathrm{p}$ & Partial $\eta^{2}$ & F & $\mathrm{p}$ & Post hoc & \\
\hline \multirow{3}{*}{$\begin{array}{l}\text { Particulate organic } \\
\text { carbon (POC) }\end{array}$} & Z-17.34 & 0 & 0.145 & \multirow[t]{3}{*}{ Z-17.04 } & \multirow[t]{3}{*}{0.001} & \multirow[t]{3}{*}{$\mathrm{R}>(\mathrm{W}=\mathrm{E})$} & $t=-0.179$ \\
\hline & S-2.37 & 0.125 & 0.011 & & & & $\mathrm{df}=191.13$ \\
\hline & I-1.44 & 0.24 & 0.014 & & & & $\mathrm{p}=0.858$ \\
\hline \multirow[t]{3}{*}{ \% clay } & Z-1.52 & 0.221 & 0.015 & \multirow[t]{3}{*}{ Z-1.49 } & \multirow[t]{3}{*}{0.227} & \multirow[t]{3}{*}{ na } & $t=-3.85$ \\
\hline & S-5.32 & 0.022 & 0.026 & & & & $\mathrm{df}=128.92$ \\
\hline & $\mathrm{I}-0.001$ & 0.999 & 0 & & & & $\mathrm{p}=0.000$ \\
\hline \multirow[t]{3}{*}{$\%$ silt } & Z-2.02 & 0.135 & 0.02 & \multirow[t]{3}{*}{ Z-2.03 } & \multirow[t]{3}{*}{0.134} & \multirow[t]{3}{*}{ na } & $t=1.03$ \\
\hline & S-0.45 & 0.502 & 0.002 & & & & $\mathrm{df}=208$ \\
\hline & $\mathrm{I}-0.11$ & 0.895 & 0.001 & & & & $\mathrm{p}=0.302$ \\
\hline \multirow[t]{3}{*}{$\%$ sand } & Z-2.03 & 0.134 & 0.02 & \multirow[t]{3}{*}{ Z-2.04 } & \multirow[t]{3}{*}{0.132} & \multirow[t]{3}{*}{ na } & $t=0.750$ \\
\hline & S-0.95 & 0.331 & 0.005 & & & & $\mathrm{df}=208$ \\
\hline & $\mathrm{I}-0.15$ & 0.863 & 0.001 & & & & $\mathrm{p}=0.454$ \\
\hline \multirow[t]{3}{*}{ Water depth (m) } & Z-36.66 & 0 & 0.264 & \multirow[t]{3}{*}{ Z-35.10 } & \multirow[t]{3}{*}{0.001} & \multirow[t]{3}{*}{$\mathrm{R}>\mathrm{E}>\mathrm{W}$} & $t=-0.301$ \\
\hline & S-0.80 & 0.372 & 0.004 & & & & $\mathrm{df}=208$ \\
\hline & I-4.66 & 0.01 & 0.044 & & & & $\mathrm{p}=0.764$ \\
\hline \multirow[t]{3}{*}{ Salinity } & Z-23.31 & 0 & 0.186 & \multirow[t]{3}{*}{ Z-14.16 } & \multirow[t]{3}{*}{0.001} & \multirow[t]{3}{*}{$E>(W=R)$} & $t=11.79$ \\
\hline & S-100.23 & 0 & 0.329 & & & & $\mathrm{df}=208$ \\
\hline & I-6.46 & 0.002 & 0.06 & & & & $\mathrm{p}=0.000$ \\
\hline Water temperature $\left({ }^{\circ} \mathrm{C}\right)$ & Z-40.23 & 0 & 0.283 & Z-1.89 & 0.153 & na & $t=-66.30$ \\
\hline & S-3184.21 & 0 & 0.94 & & & & $\mathrm{df}=146.51$ \\
\hline & I-55.88 & 0 & 0.354 & & & & $\mathrm{p}=0.001$ \\
\hline Dissolved oxygen $\left(\mathrm{mg} \mathrm{l}^{-1}\right)$ & Z-46.56 & 0 & 0.313 & Z-13.49 & 0.001 & $\mathrm{~W}>(\mathrm{E}=\mathrm{R})$ & $t=17.69$ \\
\hline & S-392.67 & 0 & 0.658 & & & & $\mathrm{df}=185.60$ \\
\hline & I-8.51 & 0 & 0.077 & & & & $\mathrm{p}=0.000$ \\
\hline Specific & Z-23.80 & 0 & 0.189 & Z-14.26 & 0.001 & $\mathrm{E}>(\mathrm{W}=\mathrm{R})$ & $t=11.90$ \\
\hline conductance (mS) & S-103.37 & 0 & 0.336 & & & & $\mathrm{df}=263.83$ \\
\hline & I-6.95 & 0.001 & 0.064 & & & & $\mathrm{p}=0.000$ \\
\hline Shannon $\left(H^{\prime}\right)$ & Z-13.34 & 0 & 0.119 & Z-4.74 & 0.01 & $\mathrm{E}>(\mathrm{W}=\mathrm{R})$ & $t=-0.434$ \\
\hline & S-0.66 & 0.418 & 0.003 & & & & $\mathrm{df}=189.92$ \\
\hline & I-0.33 & 0.721 & 0.003 & & & & $\mathrm{p}=0.665$ \\
\hline Simpson $(1-\lambda)$ & Z-10.07 & 0 & 0.092 & Z-3.11 & 0.047 & $E=W=R$ & $t=-3.56$ \\
\hline & S-8.94 & 0.003 & 0.043 & & & & $\mathrm{df}=202$ \\
\hline & I-0.183 & 0.833 & 0.002 & & & & $\mathrm{p}=0.000$ \\
\hline
\end{tabular}

non-normal and transformation $\left(\log _{10}\right)$ did not allow us to meet the assumptions. Following Underwood (1997), we used outcomes of these analyses in a hierarchical and heuristic fashion (Table 1). Season appeared to be the most influential variable in many of the 2-way ANOVA model results: $45.5 \%$ of all tests had $\mathrm{p} \leq 0.01$ for interactions and $60.0 \%$ had nonmeaningful (small) partial $\eta^{2}$. The 4 water quality variables differed by season (2-way ANOVA; Table 1, Table S3 in the Supplement), with salinity, DO, and specific conductance being higher in fall than spring, and water temperature and Simpson's evenness higher in spring than fall (Tables 1 \& S3). Water depth did not differ by season (all tests; Tables 1 \& S3), but river stations were generally deeper, on average, than east stations and both were deeper than west stations (1-way ANOVA; Tables 1 \& S3). Salinity, specific conductance, and Shannon diversity were greater in the east than the other 2 zones (1-way ANOVA; Tables 1 \& S3). In contrast, water temperature and Simpson's evenness did not differ among zones, and DO was greater in the west than the other 2 zones (1-way ANOVA; $_{i}$ Tables 1 \& S3). No differences were noted by zone for $\%$ silt, $\%$ sand, and $\%$ clay or by season for $\%$ silt and \% sand (Tables $1 \&$ S3); \% clay was greater in spring than fall. Finally, POC was greater in the river zone than both west and east zones but did not differ seasonally (Tables 1 \& S3). 
Overall macrobenthic density (ind. $\mathrm{m}^{-2}$ ) varied by zone and season, with higher densities in the west than east and river zones, and fall densities were always greater, on average, regardless of zone. Collections in the west fall period averaged 7533 ind. $\mathrm{m}^{-2}$ (range: 43-8652) compared to only 1453 ind. $\mathrm{m}^{-2}$ (174-2957) in the west spring collections. In the east fall period, mean density was 3272 ind. $\mathrm{m}^{-2}$ (60911522), but in east spring collections it was only 1101 ind. $\mathrm{m}^{-2}(0-23522)$. Finally, river fall collections averaged 1734 ind. $\mathrm{m}^{-2}$ (217-6087) compared to 1169 ind. $\mathrm{m}^{-2}(0-5174)$ in river spring collections.

\section{Data reduction}

We collected 158 total taxa among all stations ( $\mathrm{n}=207$ ) and seasons $(\mathrm{n}=2)$ distributed among 670435 individuals, with a mean density of 3177 ind. $\mathrm{m}^{-2}$ per station. After we eliminated rare taxa, based on procedures noted above, 33 taxa remained among stations $(\mathrm{n}=158)$ and seasons $(\mathrm{n}=2)$ distributed among 554435 individuals, with a mean density of 16801 ind. $\mathrm{m}^{-2}$ per station. Descriptive statistics for these reduced taxa by zone and season are given in Table S1. The majority of these abundant taxa were found to be either primary or secondary prey (Brooks \& Sulak 2005).

\section{Multivariate analyses}

The PCA of 5 physical variables of both east and west zones seasonally produced 2 meaningful components, accounting for $84.6 \%$ of the total variation (Table 2) in the original data set. PC1 accounted for $69.9 \%$, whereas PC2 accounted for an additional $14.7 \%$, although the eigenvalue of PC2 was only 0.733. All original variables loaded onto PC1 except water depth, suggesting that it is a composite sediment structure axis, whereas depth loaded heavily on PC2 (Table 3). PC3 and PC4 did not account for

Table 2. Summary of the PCA for square-root transformed and normalized physical-chemical data set by season and zone

\begin{tabular}{|cccc|}
\hline PC & Eigenvalues & \% variation & $\begin{array}{c}\text { Cumulative \% } \\
\text { variation }\end{array}$ \\
\hline 1 & 3.50 & 69.9 & 69.9 \\
2 & 0.73 & 14.7 & 84.6 \\
3 & 0.51 & 10.3 & 94.9 \\
4 & 0.26 & 5.1 & 100 \\
\hline
\end{tabular}

much variation and were not considered further. Five stations that appeared at the extreme upper right end of the PCA plot were in the east zone in fall and spring, and depth ranged from 10.50 to $14.30 \mathrm{~m}$ (Fig. 3A) compared to the maximum depth of all other stations, which was $\leq 3.80 \mathrm{~m}$. The west spring station in the lower right of the PCA plot had a com-

Table 3. Summary of PCA loadings of the original physical variables onto the principal components by season and zone. Only bold original variables $|\geq 0.400|$ are considered useful to name components (Hair et al. 1984). POC: particulate organic carbon

\begin{tabular}{|lrr|}
\hline Variable & PC1 & PC2 \\
\hline \% sand & $\mathbf{- 0 . 5 1 4}$ & 0.271 \\
\% silt & $\mathbf{0 . 4 7 7}$ & -0.403 \\
\% clay & $\mathbf{0 . 4 1 7}$ & 0.142 \\
POC $\left(\mu \mathrm{mg}^{-1}\right)$ & $\mathbf{0 . 4 6 8}$ & -0.041 \\
Water depth $(\mathrm{m})$ & 0.339 & $\mathbf{0 . 8 6 2}$ \\
\hline
\end{tabular}
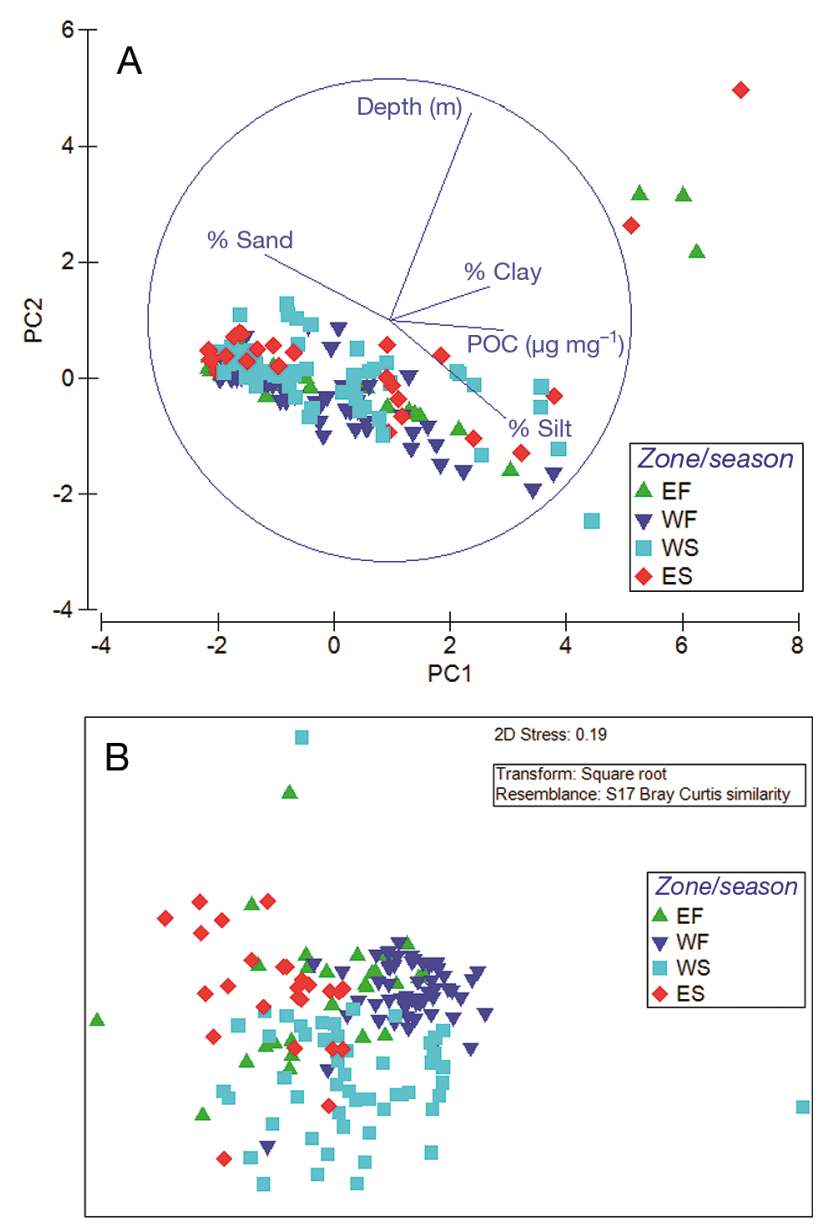

Fig. 3. (A) PCA of the reduced set of 5 physical variables by zone and season. EF: east fall, WF: west fall, WS: west spring, ES: east spring. (B) Non-metric MDS ordination of the reduced set of macrobenthic density data by zone and season 
bination of relatively high POC $\left(20.4 \mu \mathrm{g} \mathrm{mg}{ }^{-1}\right)$, high $\%$ silt $(77 \%)$, and high \% clay $(13 \%)$ compared to all other stations (Fig. 3A).

The MDS of the macrobenthic density data indicated that the $2 \mathrm{D}$ fit was appropriate (stress $=0.19$ ). The ordination plot showed low to moderate separation of east and west as well as the seasonal stations (Fig. 3B). The macrobenthic assemblages differed significantly, however, by zone (PERMANOVA; pseudo- $F=14.25$, p [perm] $=0.001$ ), season (pseudo$F=15, \mathrm{p}[$ perm $]=0.001)$, and zone $\times$ season interaction (pseudo- $F=5.46, \mathrm{p}[\mathrm{perm}]=0.001$ ). The square root of the estimates of components of variation indicated that season (20.41) accounted for more variation than zone (19.86) or the interaction term (16.30). Decomposing the interaction term with pairwise pseudo- $t$-tests indicated that west macrobenthic density was greater than east density in the fall (pseudo$t=3.25, \mathrm{p}[$ perm $]=0.0001$ ) and spring (pseudo- $t=$ 3.03, p [perm] = 0.0002), with a 33.58 fall mean similarity between zones but only a 24.22 mean similarity between zones in spring. The HMD test indicated no significant deviation from centroids for zone (pseudo$t=0.36$, p [perm] $=0.611$ ); mean deviation from centroids for the west zone was $47.21( \pm 1.01 \mathrm{SE})$ and east zone was 48.23 ( \pm 1.57$)$. In contrast, there was a significant season effect (pseudo- $t=4.52$, $\mathrm{p}$ [perm] $=$ $0.0002)$, with mean deviation from centroids of 41.85 $( \pm 1.45)$ for fall and $50.46( \pm 1.21)$ for spring. Thus, it appears that macrobenthic assemblages collected in spring have more multivariate dispersion than those collected in fall, which supports the reduced mean similarity in spring noted above.

The reduced taxa assemblage consisted of nemerteans, 19 polychaetes, 2 oligochaetes, 2 gastropods, 2 bivalves, 1 cumacean, 1 isopod, 3 amphipods, 1 chironomid, and 1 phoronid worm (Table S1). SIMPER analyses showed that the largest mean similarity among stations was in the west (40.79) followed by the east zone (33.38), whereas for seasons, mean similarity of macrobenthos density for the fall (46.03) was greater than spring stations (32.07). These ranked group similarity patterns were supported by the HMD patterns, illustrating that east zones were less similar and more dispersed compared to west zones, as were spring collections compared to fall.
Fourteen taxa contributed $70.86 \%$ toward separation of density estimates by zone (Table 4). Pairwise SIMPER comparisons indicated that 7 taxa (Mediomastis ambiseta, Streblospio gynobranchiata, Paranais litoralis, tubificid worms, Leitoscolopis fragilis, Edotea triloba, Cyclaspis varians) had higher densities in the west compared to 6 taxa (Acetocina canaliculata, nemerteans, Paraprionospio pinnata, Aricidea philbinae, Rictaxis punctostriatus, Phoronis worms) in the east, with 1 polychaete being similar (Scoletoma verrilli). In contrast, the same comparison by season indicated that 11 taxa comprised $70.43 \%$ of the seasonal separation, with 10 taxa (M. ambiseta, $P$. litoralis, S. gynobranchiata, nemerteans, A. canaliculata, L. fragilis, C. varians, tubificid worms, Glycinde solitaria, P. pinnata) having higher densities in fall compared to only 1 in spring (E. triloba; Table 5).

Finally, the reduced macrobenthic assemblage pattern was significantly correlated to the physical variable patterns (BEST, global $\mathrm{R}=0.277, \mathrm{p}<0.01$ ). Although this pattern-match procedure appears to be a weak relationship, commonly correlated physical variables were \% silt and water depth, followed by POC and \% silt (Table 6). The pairwise Spearman's correlation coefficients of the 33 taxa produced 13 taxa with significant correlations (Table 7) with depth (8 polychaetes, 2 oligochaetes, 1 cumacean, 1 amphipod, and chiromonids) and 14 taxa with \% silt (nemerteans, 10 polychaetes, 1 oligochaete, and chiromonids; Table 7); however, only 6 taxa exhibited significant correlations with both variables. In

Table 4. Mean pairwise square-root transformed density of macrobenthic taxa between zones (west vs. east) from the Pascagoula River estuary based on SIMPER analysis. Taxa are listed in order of their contribution to the mean dissimilarity between zones with a cutoff when the cumulative percent contribution approaches $70 \%$. LPTL: lowest possible taxonomic level

\begin{tabular}{|lcccc|}
\hline \multirow{2}{*}{ Taxon } & \multicolumn{2}{c}{ Mean density } & Mean (SD) & Contribution \\
& West & East & dissimilarity & $(\%)$ \\
\hline Mediomastis ambiseta & 43.22 & 22.71 & $14.04(1.31)$ & 19.82 \\
Acetocina canaliculata & 5.52 & 9.78 & $5.83(0.96)$ & 8.23 \\
Nemertea (LPTL) & 7.09 & 10.37 & $5.20(1.07)$ & 7.34 \\
Streblospio gynobranchiata & 10.47 & 1.57 & $4.92(0.86)$ & 6.95 \\
Paranais litoralis & 7.39 & 2.29 & $2.91(0.54)$ & 4.11 \\
Paraprionospio pinnata & 1.72 & 3.20 & $2.23(0.65)$ & 3.14 \\
Tubificid (LPTL) & 3.43 & 2.05 & $2.20(0.67)$ & 3.11 \\
Leitoscolopis fragilis & 5.68 & 1.15 & $2.17(0.74)$ & 3.06 \\
Edotea triloba & 2.72 & 1.12 & $2.04(0.57)$ & 2.88 \\
Aricidea philbinae & 0.81 & 2.96 & $1.92(0.44)$ & 2.72 \\
Cyclaspis varians & 4.89 & 0.73 & $1.84(0.60)$ & 2.60 \\
Rictaxis punctostriatus & 1.48 & 3.19 & $1.75(0.64)$ & 2.47 \\
Phoronis (LPTL) & 0.57 & 2.40 & $1.58(0.57)$ & 2.24 \\
Scoletoma verrilli & 1.50 & 1.88 & $1.56(0.57)$ & 2.20 \\
Total cumulative \% & & & & 70.86 \\
\hline
\end{tabular}


Table 5. Mean pairwise square-root transformed density of macrobenthic taxa between seasons (fall vs. spring) of physical-chemical factors from the Pascagoula River estuary based on SIMPER analysis. LPTL: lowest possible taxonomic level

\begin{tabular}{|lcccc|}
\hline \multirow{2}{*}{ Taxa } & \multicolumn{2}{c}{ Mean density } & Mean (SD) & Contribution \\
& Fall & Spring & dissimilarity & $(\%)$ \\
\hline Mediomastis ambiseta & 53.11 & 18.97 & $17.93(1.73)$ & 24.59 \\
Paranais litoralis & 11.14 & 0.00 & $5.04(0.72)$ & 6.91 \\
Streblospio gynobranchiata & 10.12 & 4.83 & $4.87(0.97)$ & 6.68 \\
Nemertea (LPTL) & 10.95 & 5.24 & $4.40(1.21)$ & 6.03 \\
Acetocina canaliculata & 7.57 & 6.25 & $4.26(0.95)$ & 5.84 \\
Leitoscolopis fragilis & 7.93 & 0.26 & $3.78(1.15)$ & 5.18 \\
Cyclaspis varians & 6.86 & 0.00 & $3.30(0.87)$ & 4.53 \\
Tubificid (LPTL) & 3.63 & 2.29 & $2.10(0.75)$ & 2.88 \\
Glycinde solitaria & 4.57 & 0.17 & $2.02(0.91)$ & 2.77 \\
Paraprionospio pinnata & 3.02 & 1.35 & $1.83(0.52)$ & 2.51 \\
Edotea triloba & 1.43 & 3.01 & $1.82(0.70)$ & 2.50 \\
Total cumulative \% & & & & 70.43 \\
\hline
\end{tabular}

particular, Capitella capitata, Mediomastis ambiseta, Streblospio gynobranchiata, Leitoscolopis fragilis, Cyclaspis varians, Apocorophoum lacustre, and Gemma gemma each had negative correlations with water depth, whereas Aphelochaeta polychaetes, Cossura delta, Magelona phyllisae, Parandalia americana, Paraprionospio pinnata, and Paranais litoralis exhibited a positive correlation with water depth (Table 7). In contrast, G. gemma, Spiophanes bombyx, and Armandia agilis each had negative correlations with \% silt whereas positive correlations were found with the remaining taxa (Table 7).
Table 6. Multivariate correlations ( $\rho$ ) between the reduced physical and reduced macrobenthic faunal resemblance matrices. The overall global $\mathrm{R}=0.277, \mathrm{p}<0.01 \%$. Displayed are top 4 models from the BEST output. POC: particulate organic carbon

\begin{tabular}{|lc|}
\hline Correlation $(\rho)$ & Variables \\
\hline 0.277 & \% silt, depth \\
0.224 & \% silt, POC, depth \\
0.205 & POC, depth \\
0.199 & \% silt, POC \\
\hline
\end{tabular}

Table 7. Summary of Spearman rank correlation coefficients ( $\rho)$ of selected taxa of the reduced macrobenthic density data set. LPTL: lowest possible taxonomic level. ${ }^{*} \mathrm{p}<0.05$, ${ }^{* *} \mathrm{p}<0.01$ (blanks indicate no significant relationship)

\begin{tabular}{|lcc|}
\hline Taxa & Depth $(\mathrm{m})$ & $\%$ silt \\
\hline Nemertean (LPTL) & & $0.188^{*}$ \\
Capitella capitata & $-0.187^{*}$ & \\
Mediomastis ambiseta & $-0.170^{*}$ & $0.388^{* *}$ \\
Aphelochaeta (LPTL) & $0.166^{*}$ & \\
Cossura delta & $0.267^{* *}$ & $0.240^{* *}$ \\
Podarkeopsis levifuscina & & $0.268^{* *}$ \\
Scoletoma verrilli & & $0.278^{* *}$ \\
Magelona phyllisae & $0.276^{* *}$ & $0.163^{*}$ \\
Armandia agilis & & $-0.360^{* *}$ \\
Leitoscoloplos fragilis & $-0.313^{* *}$ & \\
Glycinde solitaria & & $0.230^{* *}$ \\
Parandalia americana & $0.208^{* *}$ & \\
Paraprionospio pinnata & $0.219^{* *}$ & $0.323^{* *}$ \\
Spiophanes bombyx & & $-0.271^{* *}$ \\
Streblospio gynobranchiata & $-0.167^{*}$ & $0.316^{* *}$ \\
Paranais litoralis & $0.273^{* *}$ & \\
Tubificid (LPTL) & & $0.281^{* *}$ \\
Gemma gemma & $-0.179^{*}$ & $-0.232^{* *}$ \\
Cyclaspis varians & $-0.266^{* *}$ & \\
Apocorophium lacustre & $-0.191^{*}$ & \\
Chiromonid (LPTL) & & $0.226^{* *}$ \\
\hline
\end{tabular}

\section{Gulf sturgeon ontogenetic zone and seasonal habitat use patterns}

A total of 11 acoustically tagged Gulf sturgeon were detected over the course of this study, with juveniles ranging from 51.0 to $87.0 \mathrm{~cm}$ FL ( $\mathrm{n}=4$ ), subadults ranging from 93.0 to $114.0 \mathrm{~cm} \mathrm{FL}(\mathrm{n}=6)$, and a single $147.0 \mathrm{~cm}$ FL adult. Our calculated occupancy values had 0.83 ( 0 detections within our particular system) added to all values in order to scale to 0 and thus make interpretations more understandable. Our occupancy index values and actual effort-adjusted number of detections were highly correlated $\left(\mathrm{r}^{2}=1.0\right)$. Gulf sturgeon occupancy patterns indicated that adults appeared to move quickly (few detec-

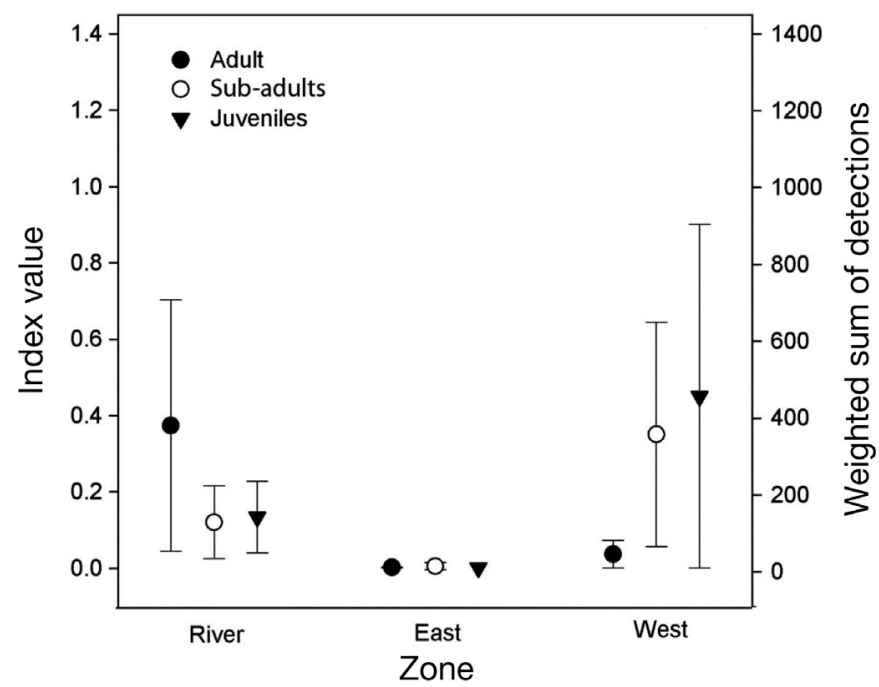

Fig. 4. Acipenser oxyrinchus desotoi. Effort-adjusted, normalized, and scaled index and weighted sum of detections by zone and size class. Error bars $=1 \mathrm{SE}$ of the mean 
tions) through the system in fall (river-west-offshore islands) and spring (reverse order; also see Havrylkoff et al. 2012) compared to longer (greater detections) but more variable occupancy for juveniles (river-west) and sub-adults in both seasons. Subadults exhibited a less variable river-west occupancy pattern. There was almost no occupancy of the east zone by any size class (Fig. 4). These patterns of habitat use were supported by 1-way ANOVA and post hoc GH tests which indicated that Gulf sturgeon occupancy differed among zones $\left(F_{2,53}=6.41, \mathrm{p}<\right.$ 0.001 ) with river and west zone occupancy being equal ( $p=0.247)$, but both had greater occupancy than the east zone (both $\mathrm{p}<0.001$ ).

\section{DISCUSSION}

Minimal information is available on the western population of Gulf sturgeon beyond life-history, genetic, and large-scale migration data; patterns of estuarine habitat use and potential benthic prey availability are based only on Florida populations. Our study is the first to examine estuarine macrobenthic spatial and temporal patterns relative to physical habitat characteristics and occupancy patterns of the western population. We did not collect some taxa suggested as primary or major prey items of eastern populations, although sampling gears were generally similar. The most parsimonious explanation is that the environments sampled among nearby (Ross et al. 2009) and distant areas (Huff 1975, Mason \& Clugston 1993, Brooks \& Sulak 2005, Harris et al. 2005, Nellis et al. 2007) clearly differed in sediment composition, water currents, and wave energy as well as different time windows of seasonal sampling, which may have driven those differences.

The overall macrobenthic density patterns in the Pascagoula River estuary varied by zone and season, but mean values were similar to those reported by Brooks \& Sulak $\left(2005 ; 0-13701\right.$ ind. $\mathrm{m}^{-2}$; overall mean $\left.=1935 \mathrm{~m}^{-2}\right)$, Harris et al. $(2005$; mean range $0-100 \mathrm{~m}^{-2}$ for the 3 main prey items), and Fox et al. (2002; overall range $0-8000 \mathrm{~m}^{-2}$ but $0-1000 \mathrm{~m}^{-2}$ in high-occupancy areas) in Florida regions. In contrast, the St. Lawrence estuarine transition zone in Canada (Nellis et al. 2007) appears to have lower mean macrobenthic densities (as expected at higher latitudes) ranging from 38 to $1295 \mathrm{~m}^{-2}$, but 300 to $700 \mathrm{~m}^{-2}$ in areas of high juvenile and sub-adult Atlantic sturgeon use. Our data on the reduced macrobenthic density assemblages indicates comparatively high mean values of $16801 \mathrm{~m}^{-2}$ by station across the study area (see Table S1 for details by zone and season). Harris et al. (2005) and Sulak et al. (2009) indicated that areas with high benthic density serve as a proxy for detecting critical Gulf sturgeon feeding habitat, and our data support this assertion.

However, macrobenthic density patterns were spatially variable even within a single coastal system like the Pascagoula River estuary, as ranked group macrobenthic similarity patterns and associated HMD indices indicated that west zone assemblages were more similar and less dispersed compared to east zones. Also, mean density of west fall was 5 times greater than west spring assemblages, whereas east fall was only 3 times higher, on average. East zone assemblages appeared patchier, as density varied considerably among stations. Similar macrobenthic spatial patterns were noted by Fox et al. (2002) among stations within Choctawhatchee Bay, Florida, with clear east and west bay patterns. Harris et al. (2005) also documented high macrobenthic density in outer Suwannee Sound compared to the Suwannee River passes in late spring.

Clearly, the time of year in which benthic resources are estimated can make a difference in the interpretation of Gulf sturgeon feeding and occupancy patterns relative to potential prey. McLelland \& Heard (2005) indicated that benthic collections should be split between fall and spring, as those dates generally coincide with before and after Gulf sturgeon foraging activities. Many of the known prey items that Gulf sturgeon consume (e.g. polychaetes, oligochaetes, amphipods) occur in greater densities in fall than in spring periods as was quantified in our study. In fact, season accounted for more explained variance in the PERMANOVA model than zone or the interaction between zone and season for the macrobenthic density patterns. Ranked macrobenthic group similarity patterns and associated HMD indices were also greater in fall compared to spring assemblages, which suggests that as young predacious fishes and decapods pulse (Rozas 1995) into the coastal area in spring/summer to forage, macrobenthos densities can be reduced (Nelson et al. 1982, Sarda et al. 1996) as patches become less dense and more variable. In fact, principal foods were spatially heterogeneous in the Suwannee River estuary (Brooks \& Sulak 2005) and varied significantly by season; summer (June to July) mean benthic density was 2562 ind. $\mathrm{m}^{-2}$, whereas the winter (February to April) mean was only $1044 \mathrm{~m}^{-2}$ for that system. Our findings, in conjunction with results obtained in other studies, suggest that fall is a better time period for quantifying density of available prey items for juveniles and sub- 
adult Gulf sturgeon because of reduced influence from other foraging fishes. This is the main time period during which juvenile and small sub-adult Gulf sturgeon use the estuary for feeding and thus is the most accurate time to determine critical feeding habitat in nearshore estuarine regions.

Our reduced macrobenthic prey composition indicated that polychaetes, oligochaetes, amphipods, isopods, bivalves, gastropods, nemerteans, and chironomids were the most numerous prey available to Gulf sturgeon, although there was variation in density by zone and season. These potential prey are typical of other areas across the Gulf sturgeon range (Brooks \& Sulak 2005, Harris et al. 2005, Ross et al. 2009) and are based on actual diets as quantified by Huff (1975), Mason \& Clugston (1993), Carr et al. (1996), and Murie \& Parkyn $(2001,2002)$ (see Table S4 in the Supplement). Much Gulf sturgeon diet data is based on adults occurring in various areas of Florida or is based on Atlantic sturgeon Acipenser oxyrinchus oxyrinchus, with few actual data from other areas of its range (Boschung \& Malloy 1956; Table S4). In general, adult diet and foraging patterns would suggest that they 'cruise' among shallow feeding sites in sandy $(>80 \%$ ) areas between 2 and $4 \mathrm{~m}$ (Mason \& Clugston 1993, Sulak \& Clugston 1998, Fox et al. 2002). However, there are some contradictory data on whether adult sturgeon, in general, spend time in areas of high macrobenthic densities. For example, Fox et al. (2002) noted that adult Gulf sturgeon spent less time in the western part of the Choctawhatchee Bay, Florida, where there was a high density of benthic invertebrates (crustaceans and annelid worms), compared to the eastern portion of the bay where \% sand was high and density of invertebrate species was low. However, density of a major adult prey item, the ghost shrimp Lepidophthalmus louisianensis, was high in high \% sand habitats. In contrast, Johnson et al. (1997) examined 275 adult Atlantic sturgeon in New Jersey marine environments which fed mainly on polychaetes and amphipods (more in fall), and isopods (more in spring); mollusks and fishes were not important prey items.

Our findings, based on the pattern-matching BEST procedure, indicate a significant but weak relationship between macrobenthic density patterns and \% silt and water depth distribution. This appears in contrast to data from eastern populations of Gulf sturgeon (Fox et al. 2002, Brooks \& Sulak 2005) where fish distribution is correlated with high sand percentages in estuarine habitats. Pairwise Spearman correlations indicated that of the 33 taxa examined, 11 had significant positive correlations with \% silt whereas 3 had negative correlations. There were almost equal positive (6) and negative (7) correlations with water depth, suggesting it was not as much of a driving variable in macrobenthic patterns as visualized in the PCA and MDS plots. The sediment characteristic appears to be more influential in macrobenthic patterns and thus juvenile and sub-adult Gulf sturgeon habitat use.

Most diet data on juvenile and sub-adult sturgeon stem from studies based on Atlantic sturgeon (Smith 1985, Moser \& Ross 1995, Haley 1998, Secor et al. 2000, Guilbard et al. 2007, Savoy 2007, McLean et al. 2013), where juveniles and sub-adults appear to prefer areas closer to the ocean characterized by low flow, shallow water, low to mid-salinity, and low-energy areas with high prey abundance (Buckley \& Kynard 1985, Hurley et al. 1987, Hall et al. 1991, Rochard et al. 2001, Guilbard et al. 2007), which support our findings in the Pascagoula River estuary. In fact, Rochard et al. (2001) indicated that although these high-occupancy areas looked similar in terms of depth and bottom type to areas with reduced occupancy, it was believed that it may be due to these having lower flows and finer sediments which may develop different benthic resources (Wooley \& Crateau 1985, Carr et al. 1996). Finally, Pearson et al. (2007) noted sediment excavations made by feeding Atlantic sturgeon in the Bay of Fundy, Canada, near shore mud flats which coincided spatially with high density areas of amphipods, bivalves, and nereid polychaetes; the greatest number of feeding excavations were in areas with the greatest density of amphipods (within $500 \mathrm{~m}$ of mean high tide). McLean et al. (2013) recently quantified that 21 sub-adult and adult Atlantic sturgeon consumed mainly tube-dwelling polychaetes (Maldanidae and Spionidae) in sandy, estuarine intertidal mudflats of Minas Basin, Canada.

Our developed occupancy index clearly was predictive of actual effort-adjusted detection numbers and thus was an appropriate metric to use for our study. Gulf sturgeon occupancy patterns indicated that adults move quickly through the system in fall (river-west-offshore islands) and spring (reverse order; also see Havrylkoff et al. 2012) compared to longer, but more variable occupancy for juveniles (river-west) and sub-adults in both seasons. Subadults exhibited a less variable river-west occupancy pattern. There was almost no occupancy of the east zone by any size class. Since we only found a weak relationship between macrobenthic density and physical characteristics, other synergistic effects may contribute to the differential habitat use patterns we describe in all size classes of Gulf sturgeon. In general, 
the wide spatial distribution pattern of tolerant taxa (i.e. oligochaetes and polychaetes) and relatively low density of sensitive species (i.e. amphipods, isopods, and mollusks; e.g. Dauer 1993, Dean 2008) across the Pascagoula River estuary likely indicates overall pollution or sediment alteration (Lytle \& Lytle 1985, Partyka \& Peterson 2008). Total sediment hydrocarbon content in Bayou Casotte, the Escatawpa River, and the industrialized east Pascagoula River distributary region of the Pascagoula River estuary ranged from 306 to $13300 \mathrm{\mu g} \mathrm{g}^{-1}$ (Lytle \& Lytle 1985); values in the west and east mouth, however, were about the same (12.9 versus $14.8 \mu^{-1} \mathrm{~g} \mathrm{~g}^{-1}$, respectively) as was \% total organic carbon (TOC; 0.85 versus 0.86 ). Furthermore, the dominant polychaete and tubificid oligochaete groups are well known indicators of contaminated sediments and, in general, pollution (Dauer 1993, Rakocinski et al. 1997, Weinstein \& Sanger 2003, Dean 2008) but are also known to be opportunistic colonizers of disturbed sites (Engle et al. 1994, Sarda et al. 1996, Lerberg et al. 2000, Dean 2008, O'Brien \& Keough 2013). Many of these taxa (species or genus level identification; see Table S4) were also found in our study, but with lower density in the east zone and in spring collections. We suggest that the most parsimonious explanation of low occupancy by Gulf sturgeon of all sizes and the associated reduced macrobenthic densities in the eastern zone result from the coupling of minor physical habitat characteristic differences within the eastern estuary, industrialization, and sediment alteration (Lytle \& Lytle 1985, Peterson et al. 2007, Partyka \& Peterson 2008), which have jointly degraded sediments and thus critical feeding habitat in the east zone compared to the west zone of the Pascagoula River estuary.

Support for this assertion can be found in a number of critical studies and is based on a multiple weightsof-evidence approach (O'Brien \& Keough 2013). Partyka \& Peterson (2008) noted that altered areas in the eastern distributary exhibited coarser sediments and greater \% TOC than non-altered areas immediately up-estuary, and this pattern may explain the absence or low abundance of key fish diet components (Hargeria rapax and Corophium [= Apocorophium] louisianum); thus, the east distributary has been viewed as having poor habitat quality for nekton. Engle et al. (1994) indicated that tubificid and polychaete worms were useful indicators of organic pollution, and Lerberg et al. (2000) noted that macrobenthic richness and diversity were significantly lower in impacted areas compared to non-impacted (control) salt marsh creeks, mainly driven by the lack of crustaceans and bivalves.
Although currently dredged materials are deposited well south of our study zones, mechanical alterations have been shown to alter not only sediment characteristics but also the density of infaunal prey items. For example, Nellis et al. (2007) noted that dredge spoil deposition areas had a low density of macrobenthos and thus feeding potential (mean = $0.096 \mathrm{~g} \mathrm{~m}^{-2}$ ), compared to control areas (mean = $0.436 \mathrm{~g} \mathrm{~m}^{-2}$ ). These activities may directly impact juvenile and sub-adult Atlantic sturgeon which feed mainly on tubificid oligochaetes; consequently, these altered areas have lower feeding potential than nonaltered control areas. Although we did not quantify many of the potential stressors in the Pascagoula River estuary, the multiple weights-of-evidence suggest that the eastern zone is much more impacted than the western zone of the estuary and therefore minimally supports Gulf sturgeon of any size class spending time in this zone. Thus, managers should strive to maintain the western distributary and Bayou Chemise in a near-pristine condition and free from development and dredge material deposition, including salt marsh creation, to aid in Gulf sturgeon recovery.

Acknowledgements. This project was funded by NOAA, NMFS Office of Protected Species. We thank M. Roberts, K. Herrington, S. Bolden, I. Baremore, and D. Rosati for technical assistance. We also thank M. Lowe, E. Satterfield, B. Ennis, S. Ashworth, E. Lang, J. McClelland, R. Heard, T. J. Fayton, C. Thompson, B. Lewis, J. Prouhet, C. Fortner, and B. J. Johnson for field and lab assistance. This research was conducted under the USM Institute of Animal Care and Use Committee no. 11092209.

\section{LITERATURE CITED}

Abele LG, Kim W (1986) An illustrated guide to the marine decapod crustaceans of Florida. Available at http://public files.dep.state.fl.us/dear/labs/biology/biokeys/decapod .pdf (accessed 9 April 2013)

Anderson MJ, Gorley RN, Clarke KR (2008) PERMANOVA+ for PRIMER: guide to software and statistical methods. PRIMER-E, Plymouth

> Boschung HT, Malloy JC (1956) A record of the lancelet, Brachiostoma caribaeum, from the stomach of a sturgeon from the Gulf coast of Alabama. Copeia 1956:116

Breder CM Jr (1929) Field book of marine fishes of the Atlantic coast from Labrador to Texas. G.P. Putnam's Sons, Knickerbocker Press, Albany, NY

Brooks RA, Sulak KJ (2005) Quantitative assessment of benthic food resources for juvenile Gulf sturgeon, Acipenser oxyrinchus desotoi, in the Suwannee River estuary, Florida, USA. Estuaries 28:767-775

> Buckley J, Kynard B (1985) Yearly movements of shovelnose sturgeon in the Connecticut River. Trans Am Fish Soc 114:813-820 
Carr SH (1983) All the way down upon the Suwannee River. Audubon Mag 85:78-101

> Carr SH, Tatman F, Chapman FA (1996) Observations on the natural history of the Gulf of Mexico sturgeon (Acipenser oxyrinchus desotoi Vladykov 1955) in the Suwannee River, southeastern United States. Ecol Freshw Fish 5: 169-174

Clarke KR, Gorley RN (2006) Primer v6: user manual/tutorial. Primer-E Ltd., Plymouth Marine Biological Laboratory, Plymouth

Cooke SJ, Paukert C, Hogan Z (2012) Endangered river fish: factors hindering conservation and restoration. Endang Species Res 17:179-191

Dadswell MJ (2006) A review of the status of Atlantic sturgeon in Canada, with comparisons to populations in the United States and Europe. Fisheries 31:218-229

Dauer DM (1993) Biological criteria, environmental health and estuarine macrobenthic community structure. Mar Pollut Bull 26:249-257

Day PR (1965) Particle fractionation and particle-size analysis. In: Black CA, Evans DD, Ensminger LE, White JL, Clark FE (eds) Methods of soil analysis. Part 1. Physical and mineralogical properties, including statistics of measurement and sampling. American Society of Agronomy, Soil Science Society of America, Madison, WI, p 545-567

Dean HK (2008) The use of polychaetes (Annelida) as indicator species of marine pollution: a review. Rev Biol Trop 56:11-38

Dynesius M, Nilsson C (1994) Fragmentation and flow regulation of river systems in the northern third of the world. Science 266:753-762

Engle VD, Summers JK, Gaston GR (1994) A benthic index of environmental condition of Gulf of Mexico estuaries. Estuaries 17:372-384

Field A (2005) Discovering statistics using SPSS, 2nd edn. Sage Publications, London

Folk RL (1980) Petrology of sedimentary rocks. Hemphill Publishing Company, Austin, TX

Fox DA, Hightower JE, Parauka FM (2002) Estuarine and nearshore marine habitat use by Gulf sturgeon from the Choctawhatchee River system, Florida. Am Fish Soc Symp 28:111-126

Green SB, Salkind NL (2008) Using SPSS for Windows and Macintosh. Analyzing and understanding data, 5th edn. Pearson Prentice Hall, Upper Saddle River, NJ

Guilbard F, Munro J, Dumont P, Hatin D, Fortin R (2007) Feeding ecology of Atlantic sturgeon and lake sturgeon co-occurring in the St. Lawrence estuarine transition zone. Am Fish Soc Symp 56:85-104

Hair JF Jr, Anderson RE, Tatham RL, Grablowsky EJ (1984) Multivariate data analysis, with readings. Macmillan Publishing, New York, NY

Haley N (1998) A gastric lavage technique for characterizing diets of sturgeons. N Am J Fish Manag 18:978-981

- Hall JW, Smith TIJ, Lamprecht SD (1991) Movements and habitats of shortnose sturgeon, Acipenser brevirostrum in the Savannah River. Copeia 1991:695-702

> Harris D, Horwath WR, Van Kessel C (2001) Acid fumigation of soils to remove carbonates prior to total organic carbon or carbon-13 isotopic analysis. Soil Sci Soc Am J 65: 1853-1856

Harris JE, Parkyn DC, Murie DJ (2005) Distribution of Gulf of Mexico sturgeon in relation to benthic invertebrate prey resources and environmental parameters in the
Suwannee River estuary, Florida. Trans Am Fish Soc 134: 975-990

Havrylkoff JM, Peterson MS, Slack WT (2012) Assessment of the seasonal use of the lower Pascagoula river estuary by Gulf sturgeon (Acipenser oxyrinchus desotoi). J Appl Ichthyol 28:681-686

Heard RW, McLelland JA, Foster JM (2002) Direct and indirect observations of the diet, seasonal occurrence, and distribution of the Gulf sturgeon, Acipenser oxyrinchus desotoi Vladykov, 1955, from the Choctawhatchee Bay system, Florida, in relation to macroinvertebrate assemblages and parasites. Report to U.S. Fish and Wildlife Service, Panama City, FL

Heard R, Hansknecht T, Larsen K (2003) An illustrated identification guide to Florida Tanaidacea (Crustacea: Peracarida) occurring in depths of less than $200 \mathrm{~m}$. Available at http://publicfiles.dep.state.fl.us/dear/labs/biology/bio keys/tanaidacea.pdf (accessed 9 April 2013)

Heard RT, Roccatagliata D, Petrescu I (2007) An illustrated guide to Cumacea (Crustacea: Malacostraca: Pericardia) from Florida coastal and shelf waters to depths of $100 \mathrm{~m}$. Available at http://publicfiles.dep.state.fl.us/dear/labs/ biology/biokeys/cumacea_guide.pdf (accessed 9 April 2013)

$>$ Hedges JI, Stern JH (1984) Carbon and nitrogen determinations of carbonate-containing solids. Limnol Oceanogr 29:657-663

> Heise RJ, Slack WT, Ross ST, Dugo MA (2004) Spawning and associated movement patterns of Gulf sturgeon in the Pascagoula River drainage, Mississippi. Trans Am Fish Soc 133:221-230

Huff JA (1975) Life history of Gulf of Mexico sturgeon, Acipenser oxyrhynchus desotoi, in the Suwannee River, Florida. Florida Marine Resources Publ. No. 16, St. Petersburg, FL

Hurley ST, Hubert WA, Nickum JG (1987) Habitats and movements of shovelnose sturgeons in the Upper Mississippi River. Trans Am Fish Soc 116:655-662

International Union for Conservation of Nature (IUCN) (2010) Sturgeon more critically endangered than any other group of species. Mar Pollut Bull 60:640-641

Johnson PG, Uebelacker JM (eds) (1984) Taxonomic guide to the polychaetes of the northern Gulf of Mexico. Final Report to the Minerals Management Service, contract 14-12-001-29091. Barry A. Vittor \& Associates, Mobile, $\mathrm{AL}$

Johnson JH, Dropkin DS, Warkentine BE, Rachlin JW, Andrews WD (1997) Food habitats of Atlantic sturgeon off the central New Jersey coast. Trans Am Fish Soc 126: 166-170

Kensley B, Schotte M (1989) Guide to the marine isopod crustaceans of the Caribbean. Smithsonian Institution Press, Washington, DC

Knowles DR, Manson C (2003) Endangered and threatened wildlife and plants: designation of critical habitat for the Gulf sturgeon. Code of Federal Regulations, 50 CFR Parts 17 and 226. Fed Reg 68:13370-13495

LeCroy SE (2004-2011) An illustrated identification guide to the nearshore marine and estuarine gammaridean Amphipoda of Florida, Vols 1-6. Florida Department of Environmental Regulation, Tallahassee, FL. Available at www.dep.state.fl.us/labs/cgi-bin/sbio/keys.asp\#keys (accessed 9 April 2013)

Lerberg SB, Holland AF, Sanger DM (2000) Responses of tidal creek macrobenthic communities to the effects of 
watershed development. Estuaries 23:838-853

Lytle TF, Lytle JS (1985) Pollutant transport in Mississippi Sound. MASGC-82-038. Mississippi-Alabama Sea Grant Consortium, Ocean Springs, MS

Mason WT, Clugston JP (1993) Foods of the Gulf sturgeon in the Suwannee River, Florida. Trans Am Fish Soc 122: 378-385

McLean MF, Dadswell MJ, Stokesbury MJW (2013) Feeding ecology of Atlantic sturgeon, Acipenser oxyrinchus oxyrinchus Mitchill, 1815 on the infauna of intertidal mudflats of Minas basin, Bay of Fundy. J Appl Ichthyol 29: 503-509

McLelland J, Heard R (2005) Analysis of benthic macroinvertebrates from northern Florida shallow coastal areas where Gulf sturgeon, Acipenser oxyrinchus desotoi, are believed to forage year 2. Final Report to the USFWS. United States Fish and Wildlife Service, Panama City, FL

Miller MJ (2004) The ecology and functional morphology of feeding of North American sturgeon and paddlefish. In: LeBreton GTO, Beamish FWH, McKinley RS (eds) Sturgeons and paddlefish of North America. Fish and Fisheries Series 27. Kluwer Academic Publishers, Dordrecht, p 87-102

Montagna PA, Palmer TA, Pollack JB (2013) Hydrological changes and estuarine dynamics. Springer Briefs in Environmental Science. Springer Publishing, New York, NY

Moser ML, Ross SW (1995) Habitat use and movements of shortnose and Atlantic sturgeons in the Lower Cape Fear River, North Carolina. Trans Am Fish Soc 124: 225-234

Moser ML, Bain M, Collins MR, Haley N and others (2000) A protocol for use of shortnose and Atlantic sturgeons. NOAA Tech Memo NMFS-OPR-18. U.S. Department of Commerce, National Oceanic and Atmospheric Administration, National Marine Fisheries Service Office of Protected Resources, Silver Spring, MD

Murie DJ, Parkyn DC (2001) Development and implementation of a non-lethal method for collection of stomach contents from sturgeon in relation to diel feeding periodicity: Phase II, consumption of brachiopods as a model food source for Gulf of Mexico sturgeon. Interim Final Report, Florida Fish and Wildlife Conservation Commission, St. Petersburg, FL

Murie DJ, Parkyn DC (2002) Critical estuarine winter feeding areas of threatened Gulf of Mexico sturgeon in the Suwannee River estuary and Blackwater Bay. Final Report to Florida Fish and Wildlife Conservation Commission, St. Petersburg, FL

Nellis P, Munro J, Hatin D, Desrosiers G, Simons RD, Guilbard F (2007) Macrobenthos assemblages in the St. Lawrence estuarine transition zone and their potential as food for Atlantic sturgeon and lake sturgeon. Am Fish Soc Symp 56:105-128

Nelson WG, Cairns KD, Virnstein RW (1982) Seasonality and spatial patterns of seagrass-associated amphipods of the Indian River lagoon, Florida. Bull Mar Sci 32:121-129

Nelson TC, Doukakis P, Lindley ST, Schreier AD and others (2013) Research tools to investigate movements, migrations, and life history of sturgeons (Acipenseridae), with an emphasis on marine-oriented populations. PLoS ONE 8:e71552

O'Brien AL, Keough MJ (2013) Detecting benthic community responses to pollution in estuaries: a field mesocosm approach. Environ Pollut 175:45-55

> Parauka FM, Duncan MS, Lang PA (2011) Winter coastal movement of Gulf of Mexico sturgeon throughout northwest Florida and southeast Alabama. J Appl Ichthyol 27: 343-350

Partyka ML, Peterson MS (2008) Habitat quality and saltmarsh species assemblages along an anthropogenic estuarine landscape. J Coast Res 24:1570-1581

Pearson NJ, Gingas MK, Armitage IA, Pemberton SG (2007) Significance of Atlantic sturgeon feeding excavations, Mary's Point, Bay of Fundy, New Brunswick, Canada. Palacios 22:457-464

> Peterson MS, Weber MR, Partyka ML, Ross ST (2007) Integrating in situ quantitative geographic information tools and size-specific, laboratory based growth zones in a dynamic river-mouth estuary. Aquat Conserv 17: 602-618

> Rakocinski CF, Brown SS, Gaston GR, Heard RW, Walker WW, Summers JK (1997) Macrobenthic responses to natural and contaminated-related gradients in northern Gulf of Mexico estuaries. Ecol Appl 7:1278-1298

> Rochard E, Lepage M, Dumont P, Tremblay S, Gazeau C (2001) Downstream migration of juvenile European sturgeon Acipenser sturio L. in the Gironde estuary. Estuaries 24:108-115

Rogillio HE, Ruth RT, Behrens EH, Doolittle CN, Granger WJ, Kirk JP (2007) Gulf sturgeon movements in the Pearl River drainage and the Mississippi Sound. N Am J Fish Manag 27:89-95

Ross ST, Slack WT, Heise RJ, Dugo MA and others (2009) Estuarine and coastal habitat use of Gulf sturgeon (Acipenser oxyrinchus desotoi) in the North-Central Gulf of Mexico. Estuar Coasts 32:360-374

Rozas LP (1995) Hydroperiod and its influence on nekton use of the saltmarsh: a pulsing ecosystem. Estuaries 18: 579-590

Sarda R, Valiela I, Forman K (1996) Decadal shifts in a salt marsh macroinfaunal community in response to sustained long-term experimental nutrient enrichment. J Exp Mar Biol Ecol 205:63-81

Savoy T (2007) Prey eaten by Atlantic sturgeon in Connecticut waters. Am Fish Soc Symp 56:157-165

Secor DH, Niklitschek EJ, Stevenson JT, Gunderson TE and others (2000) Dispersal and growth of yearling Atlantic sturgeon, Acipenser oxyrinchus, released into Chesapeake Bay. Fish Bull 98:800-810

Smith RN, Tillman MF (1991) Endangered and threatened wildlife and plants: threatened status for the Gulf sturgeon. Code of Federal Regulations, 50 CFR Part 17. Fed Reg 56:49653-49658

Smith TIJ (1985) The fishery, biology, and management of Atlantic sturgeon, Acipenser oxyrhynchus, in North America. Environ Biol Fishes 14:61-72

Southwood TRE (1977) Habitat, the templet for ecological strategies? J Anim Ecol 46:337-365

Sulak KJ, Clugston JP (1998) Early life history stages of Gulf sturgeon in the Suwannee River, Florida. Trans Am Fish Soc 127:758-771

Sulak KJ, Clugston JP (1999) Recent advances in the life history of Gulf of Mexico sturgeon, Acipenser oxyrinchus desotoi, in the Suwannee River, Florida, USA: a synopsis. J Appl Ichthyol 15:116-128

Sulak KJ, Randall MT, Edwards RE, Summers TM and others (2009) Defining winter trophic habitat of juvenile Gulf sturgeon in the Suwannee and Apalachicola river- 
mouth estuaries, acoustic telemetry investigations. J Appl Ichthyol 25:505-515

Tatum FJ (1984) Sturgeon fishing, Suwannee River, 1984. Final Report, Caribbean Conservation Corps, Gainesville, FL

Tunnel W, Andrews J, Barrera NC, Moretzsohn F (2010) Encyclopedia of Texas seashells: identification, ecology, distribution, and history. Texas A\&M University Press, College Station, TX

Underwood AJ (1997) Experiments in ecology: their logical design and interpretation using analysis of variance. Cambridge University Press, Cambridge

USFWS (United States Fish and Wildlife Service) (1993) Standard operating procedures for sturgeon. USFWS, Panama City Field Office, Panama City, FL

Vecsei P, Peterson D (2004) Sturgeon ecomorphology: a descriptive approach. In: LeBreton GTO, Beamish FWH,

Editorial responsibility: Eric Gilman,

Honululu, Hawaii, USA
McKinley RS (eds) Sturgeons and paddlefish of North America. Fish and Fisheries Series 27. Kluwer Academic Publishers, Dordrecht, p 103-133

Weinstein JE, Sanger DM (2003) Comparative tolerance of two estuarine annelids to fluoranthene under normoxic and moderately hypoxic conditions. Mar Environ Res 56: 637-648

Wooley CM (1985) Evaluation of morphometric characters used in taxonomic separation of Gulf of Mexico sturgeon, Acipenser oxyrhynchus desotoi. In: Binkowski F, Doroshov SI (eds) North American sturgeon: developments in environmental biology of fishes, Vol 6. Dr. W. Junk, Dordrecht, p 97-103

Wooley CM, Crateau EJ (1985) Movement, microhabitat, exploitation, and management of Gulf of Mexico sturgeon, Apalachicola River, Florida. N Am J Fish Manag 5: 590-605

Submitted: May 15, 2013; Accepted: September 21, 2013 Proofs received from author(s): November 10, 2013 